\title{
THE USE OF ACCIDENT INCIDENCE RATE RATIOS TO EVALUATE AGE RELATED SAFETY IN AUSTRALIAN HEAVY VEHICLE DRIVERS IN THE STATE OF NEW SOUTH WALES (1999-2006)
}

Maya Guest, ${ }^{1}$ May Boggess ${ }^{1}$ University of Newcastle, Callaghan, Australia; ${ }^{2}$ Texas AGM University, College Station, USA

10.1136/oemed-2011-100382.266

Objectives The objective was to estimate annual accident incidence rate ratios (AAIRR) of younger and older heavy vehicle drivers relative to middle age drivers using data from New South Wales (NSW).

Methods This study analyses all accidents involving a heavy vehicle (categorised as passenger and light commercial, rigid trucks and articulated trucks) reported in the NSW Roads and Traffic Authority Accident Database. Poisson regression modeling was used to estimate AAIRR where the response was the number of vehicles involved in accidents and the exposure was the number of kilometres travelled each year (gender, age, year and vehicle type) as estimated by the Australian Bureau of Statistics Survey of Motor Vehicle Use.

Results A total of 26146 accidents occurred in NSW in the observation period involving a total of 54191 traffic units; 13451 observations were excluded leaving 40740 observations representing 20401 accidents. The AAIRR analysis showed that younger drivers under the age of 26 years are at a greater risk of being involved in an accident involving a heavy vehicle than older drivers. They are safest in rigid trucks. Drivers over the age of 64 years are at least risk particularly when driving rigid or articulated trucks.

Conclusions We conclude that encouraging younger drivers ( $<26$ years), particularly, to drive rigid trucks and the retention of older drivers is appropriate without this endangering workplace and road safety. 